Urdimento

REVISTA DE ESTUDOS EM ARTES CÊNICAS

E-ISSN 2358.6958

\title{
Contagiar sonhos e resistências: A casa, a tela e o entre
}

Bruna Martins Reis

Flavio Rabelo

Dora de Andrade Silva

Carlos Roberto Cavalcante de Rezende

\section{Para citar este artigo:}

REIS, Bruna Martins; RABELO, Flavio; SILVA, Dora de Andrade; REZENDE, Carlos Roberto Cavalcante de. Contagiar sonhos e resistências: A casa, a tela e o entre. Urdimento - Revista de Estudos em Artes Cênicas, Florianópolis, v. 3, n. 42, dez. 2021.

doi DOl: http:/dx.doi.org/10.5965/1414573103422021e0303

Este artigo passou pelo Plagiarism Detection Software| iThenticate 


\section{Contagiar sonhos e resistências: A casa, a tela e o entre}

Bruna Martins Reis ${ }^{1}$

Flavio Rabelo²

Dora de Andrade Silva ${ }^{3}$

Carlos Roberto Cavalcante de Rezende ${ }^{4}$

\section{Resumo}

Este artigo aborda alguns aspectos criativos e pedagógicos da experiência da oficina "Só os sonhos não temem o contágio", realizada pelo Núcleo Fuga! de forma online no contexto da pandemia COVID 19. No que se refere ao estudo da presença neste modo remoto, exploramos algumas propostas acionadas pelas ideias de contágio e pertencimento, em uma prática apoiada na Técnica Klauss Vianna de dança e educação somática e em programas performativos, articulados à práticas cartográficas. No estudo criativo das composições com o ambiente da casa, as proposições visavam escavar possibilidades performativas ao se visitar as imagens-enigmas dos sonhos, como tensionamento para provocar a relação entre arte, inconsciente e resistência.

Palavras-chave: Programas performativos. Práticas cartográficas. Técnica Klauss Vianna. Sonhos. Resistência.

Doutorado em Artes da Cena pela Universidade Estadual de Campinas (Unicamp). Mestrado em Saúde Coletiva pela Unicamp. Graduação pela Universidade Estadual Paulista (Unesp - Assis). Professora do Curso de Psicologia da Uniararas. bru_psi@yahoo.com.br

(9) http://lattes.cnpq.br/7638989684202336 (iD https://orcid.org/0000-0001-6285-8131

2 Doutorado em Artes da Cena Universidade Estadual de Campinas (Unicamp - FAPESP). Mestrado em Artes (Unicamp/FAPESP). Graduado em Licenciatura em Artes Cênicas (UFAL). flaurabelo@gmail.com

(9) http://lattes.cnpq.br/4814984804770525 (iD https://orcid.org/0000-0001-8806-0347

${ }^{3}$ Doutora em Artes da Cena Universidade Estadual de Campinas (Unicamp). Mestrado em Ciência da Arte pela Universidade Federal Fluminense (UFF). Bacharel e Licenciada em Dança (UNICAMP). Professora dos cursos de Artes Cênicas, de Dança e de Teatro, e do Mestrado Profissional em Artes da Universidade Federal Mato Grosso do Sul (UFMS). doradeandrade@gmail.com

http://lattes.cnpq.br/3545831664608412 (iD https://orcid.org/0000-0001-5106-3624

${ }^{4}$ Mestre em Artes da Cena pela Universidade Estadual de Campinas (Unicamp). Especialista em Gestão Cultural contemporânea pelo Instituto Singularidades e Itaú Cultural. Formação como ator pela Escola de Arte Dramática - EAD /ECA/ USP). carbonario68@gmail.com

(9) http://lattes.cnpq.br/5946764227377137 (iD) https://orcid.org/0000-0002-7721-4176 
Contaminating dreams and resistances: The house, the screen and the between

\begin{abstract}
This article approaches some creative and pedagogical aspects of the experience of the workshop "Only Dreams Don't Fear the Contagion", accomplished by Núcleo Fuga! In online form in the context of the COVID 19 pandemic. Regarding the study of presence in this remote mode, we explore some proposals triggered by the ideas of contagion and belonging, in a practice based on Klauss Vianna Technique of dance and somatic education and on performative programs, jointed to cartographic practices. In the creative study of the compositions with the environment of the house, the proposals aimed performative possibilities by visiting the enigma-images of dreams, as a tension to provoke the relationship between art, the unconscious and resistance.
\end{abstract}

Keywords: Performative programs. Cartographic practices. Klauss Vianna Technique. Dreams. Resistance.

Contaminando sueños y resistencias: La casa, la pantalla y el entre

\title{
Resumen
}

Este artículo aborda algunos aspectos creativos y pedagógicos de la experiencia del taller "¡Solo los Sueños No Temen al Contagio", conducido por Núcleo Fuga! online en el contexto de la pandemia de COVID 19. Con respecto al estudio de la presencia en este modo remoto, exploramos algunas propuestas desencadenadas por ideas de contagio y pertenencia, en una práctica sustentada en la Técnica Klauss Vianna de danza y educación somática, y en programas performativos, articulados a prácticas cartográficas. En el estudio creativo de las composiciones con el ambiente de la casa, las propuestas apuntaban a excavar posibilidades performativas em visitar las imágenes-enigmas de los sueños, como tensión para provocar la relación entre arte, inconsciente y resistencia.

Palabras clave: Programas performativos. Prácticas cartográficas. Técnica Klauss Vianna. Sueños. Resistencia. 


\author{
con'ta.gi-ar - Conjugar \\ (contágio + -ar) \\ verbo transitivo e pronominal \\ 1. [Medicina] Transmitir ou adquirir doença por contágio. \\ = CONTAMINAR, INFECTAR \\ 2. [Figurado] Espalhar-se, propagar-se. \\ verbo transitivo \\ 2. [Figurado] Exercer influência sobre. = AFETAR, ATINGIR, \\ INFLUENCIAR \\ 4. Ter efeito nocivo. $=$ CORROMPER ${ }^{5}$
}

Carrega no corpo a lembrança do ontem e do anteontem. 2016 golpes. Upload de suspensão de céu sem ar. Não lembra do sonho de hoje. Download de 491.164 mil mortes por Covid 19. O Pesadelo Brasil Verde Amarelo Pandêmico, em carne, osso e hediondez, ocupa o Planalto Central Fake Live 17. Passa boi, passa a boiada, grilagem, madeira contrabandeada, florestas são queimadas no esquecimento. E a onça? Protozoário ou vírus? Em terra de Cloroquina, quem usa máscara é no mínimo sensato. Vacina já! Sente saudade de abraçar numa esquina de rua e se perder no tempo do coração. Em mundo de distanciamentos, reais ou virtuais, só os sonhos não temem o contágio? Dos pés à cabeça, banha-se de álcool em gel e clica no link Zoom Meeting da tela. Pequena pausa. Loading. Um mosaico de 20 janelas se abre num horizonte plano diante dos olhos. Ficção ou realidade? Uma grande casa ocupada, cheia de gente suando sem cheiro, um mundo temporário possível sustentado por fios invisíveis, bytes e sonhos. Desperta.

A comunicação virtual e remota já é uma realidade disponibilizada há tempos no imaginário dos filmes de ficção, e mais recentemente, para diversos setores de produção no mundo. Entretanto, nunca este 'modus operandi' se fez tão preponderante, necessário e vital quanto neste momento em que vivemos na história da humanidade. Embora o Núcleo FUGA! já transite e utilize o meio virtual 
como um dos seus principais territórios de planejamento, criação e pesquisa desde o início do Projeto Casa, ${ }^{7}$ em 2014, é somente no ano de 2020, em consequência do pressionamento pandêmico pelo Covid-19, nas articulações de convivência presencial, que o coletivo cria, produz e realiza o seu primeiro projeto totalmente remoto via plataforma Zoom Meeting e WhatsApp.

\section{De caráter processual e cartográfica, a "IV Residência Artística do Projeto cAsa}

- virtual: Só os sonhos não temem o contágio"» foi acionada apenas com integrantes do coletivo durante vinte e um dias, tendo como colaboradores

residem nas seguintes cidades: Campinas/SP, Campo Grande/MS, Diamantina/MG e São Paulo/SP. Para saber mais, acesse nosso artigo publicado na Revista Manzuá - 2020 https://periodicos.ufrn.br/manzua/article/view/23213

7 Esta fase da pesquisa se articula através de dois projetos simultâneos e interligados desenvolvidos pelo Fuga! entre 2014 e 2020. Os dois projetos são:

1 - Projeto cAsa - ainda em desenvolvimento e que envolve uma série de ações artísticas e pedagógicas, que exploram a relação do ambiente da casa e as sutilezas do cotidiano observado como dança. Tal projeto tem as seguintes obras: a Performance C.A.S.A. Caminho Aberto, Sempre Aberto [1], a Oficina Desculpas Cotidianas para Dançar, o Vídeo dança - Quintal [2], a Intervenção Urbana - O que você está fazendo agora? [3], os Jogos Cênicos - Encontros Íntimos, Do que ainda não existe ao que já não existe mais e Parece Cinema [4] e a Residência Artística Virtual Só os sonhos não temem o contágio [5].

2 - Projeto Práticas Cartográficas - finalizado em 2019, envolveu uma série de ações de atravessamento dentro do Simpósio Reflexões Cênicas Contemporâneas [6], realizadas entre os anos de 2015 e 2019. As ações realizadas "tensionaram as relações entre um ambiente de pesquisa acadêmica em arte e ações artísticas e processos criativos. Tal tensionamento de caráter performativo visa gerar outras dinâmicas de fruição entre as partes. Potencializando, assim, conexões entre conteúdos variados, valorizando os aspectos subjetivos relacionados à produção e circulação de conhecimento, através da abertura de espaços de contaminação entre as pesquisas e as práticas criativas [7]".

[1] Para assistir ao vídeo performance, acesse: https://youtu.be/Byl9zXAPmME

[2] Para assistir ao vídeo dança, acesse: https://youtu.be/3ylhuRlGCIU

[3] Para assistir ao vídeo da Intervenção Urbana, acesse: https://youtu.be/TKxom5jSTgA

[4] Para assistir ao vídeo do Jogo Cênico, acesse: https://youtu.be/nY5 fqfEFql

[5] Para ler artigo escrito a partir dessa Residência Artística: https://periodicos.ufrn.br/manzua/article/view/23213/13699

[6] Para saber mais sobre o Simpósio: https://re4919.wixsite.com/simposiolume

[7] Texto de descrição das Práticas Cartográficas realizadas pelo Núcleo Fuga! nos materiais de divulgação do Simpósio.

${ }^{8}$ A IV Residência Artística do Projeto cAsa - virtual: Só os sonhos não temem o contágio foi iniciada em 10 julho, indo até o dia 31 do mesmo mês. Nessa quarta edição das residências artísticas do Projeto cAsa recebemos como convidados os artistas alagoanos Renata Voss e René Guerra. A partir dos interesses transdisciplinares deste processo, desta vez o foco da pesquisa de linguagem e das criações estava na relação entre as artes presenciais com o audiovisual e a fotografia, atravessados pelas imagens-enigmas dos sonhos e das ruínas. Para saber mais, acesse nosso artigo publicado na Revista: https://periodicos.ufrn.br/manzua/article/view/23213 
criativos os artistas alagoanos Renata Voz e René Guerra.

Em abril de 2021, uma possibilidade nos convoca, e somos selecionados para compor a programação do $2^{\circ}$ Festival Sala de Giz de Teatro - edição online ${ }^{9} \mathrm{com}$ o mesmo projeto "Só os sonhos não temem o contágio", mas em formato de oficina, com duração de apenas três dias. Assim, esta nova versão surge como um desdobramento das urgências cartografadas durante a Residência Artística realizada internamente em 2020, e agora direcionada e compartilhada abertamente com o público em geral.

Essa Oficina se propõe a ser um laboratório de criação intensivo, convocando a esboçar cenas e personas, a partir do estudo da relação corpo-tempo-espaço-câmera, experimentando na prática ajustes de enquadramentos, profundidade de campo, proporção entre objetos no quadro, estudos de planos e composições fílmicas. A pesquisa de movimento apoia-se na Técnica Klauss Vianna de dança e educação somática, articulada com programas performativos, cartografias corporais, narrativas em derivas e jogos. No estudo criativo com a nossa casa, escavaremos máscaras, clichês, fachadas e outras paisagens ao visitar as imagens-enigmas dos nossos sonhos. ${ }^{10}$

Abraçar este novo modo de trânsito e convivência social na ambiência digital remota exige disposição, tempo e investimento financeiro, tanto público quanto privado. E no campo das artes, mais especificamente das artes presenciais, acrescenta-se ainda doses de transgressão e criatividade para tentar dar carne e osso à relação com o que se faz trama invisível de códigos na bi-dimensionalidade de uma tela. É teatro, é dança, é cinema, é 'live', é oficina, é palestra, é reunião de trabalho, é o quê?

A criação de forma remota e digital parece convocar outros alinhamentos, outras escutas e suportes que podem promover retorcimentos pedagógicos, por vezes inaugurados ou redesenhados nesta comunicação online. Por exemplo, no aspecto da oralidade e da escrita utilizada na comunicação com os participantes, seja nos momentos síncronos ou assíncronos, uma outra presença parece ser

${ }^{9}$ Festival organizado pela companhia de Teatro Sala de Giz, localizada e atuante na cidade de Juiz de Fora (MG). Para saber mais, acesse: http://www.saladegiz.com.br/ 
necessária para performar nesta realidade digital, uma presença de crença e contágio, fé cênica em modo infinito, que se faz nos afetos de ruídos e 'delays', travamentos de tela, quedas de sinal de internet, da ocupação dos cotidianos de cada casa, um mosaico psicogeográfico que precisa ser abraçado como mais um dos acontecimentos e composições possíveis neste território compartilhado em múltiplas camadas.

O que é vida aqui? O que é cena aqui? É ficção? Você está dormindole? O que é vida aqui? O que é cena aqui? É ficção? Você está acordado/e? O que é vida aqui? O que é cena aqui? É ficção? Você está sonhando/e? O que é vida? O que é cena? É ficção? É Sonho?

\section{Pausa.}

o que acontece ali naquela pequena janela que chega na sala de casa quando a campainha toca? A comida queimou e você sentiu o cheiro aí do outrale/o lado na sua cozinha? Suamos juntos? Sentimos a temperatura e o cheiro do outra /e/o? Estou sozinha/e/o ou estamos juntas/es/os agora?"1

Para além dos desafios estruturais, a pedagogia das Artes no virtual parece instaurar uma espécie de materialidade de um "sonhar acordado". A câmera se apresenta como o dispositivo portal para construção deste mundo. O espelhamento, no trânsito de realidades simultâneas e uma constante produção de duplos quase que infinitos, que atualizam constantemente a percepção da realidade - o olho que olha a tela é capturado pela outra tela que olha o olho do outro lado que vê a si que é similar e não o mesmo, mas uma projeção do que possa ser real - o que ouço é também reprodução projetada de códigos que formam imagens captadas pelo cérebro, sensações se espalham pela pele, e ocupam um corpo outro, não só organismo, mas também imaginado. E se assim se imagina, acredita-se? Percorrer a ambiência digital durante a oficina se fez campo de investigação em temperatura curiosa e cartográfica. A cada passo uma descoberta ou recuo, sobrevoos e pausas, dança que se faz na surpresa. Na dúvida, cultive outras perguntas. O que está acontecendo agora?

Trechos de comandos verbais acionados durante a oficina. Ao longo do artigo, esse tipo de textualidade será grafado em itálico. 


\section{Da estrutura da oficina ou como programar contágios e sonhos}

No âmbito da produção deste trabalho, algumas escolhas foram adotadas como pistas para traçar o caminho a ser percorrido ao longo de sua preparação e execução. Desta forma, estabeleceram-se três territórios digitais de ocupação a serem investigados e que se interligam espacial e temporalmente durante o período de acionamento da oficina: e-mail, aplicativo WhatsApp e a plataforma zoom Meeting.

01 - E-mail de abertura ou primeiros contornos

Uma semana antes do início desta oficina, os participantes recebem um email de abertura no qual os acordos iniciais são propostos, assim como uma série de provocações organizadas na forma de programas performativos, nomeadas de Enigmas, são enviadas. Segue abaixo, um trecho desse e-mail de abertura:

"Primeiramente, entendemos este nosso espaço de troca como coletivo e horizontal, ou seja, cada pessoa é responsável pelo cuidado e a atenção do que é produzido aqui em relação a todes. Chegue pontualmente. Cada instante nesta jornada tem seu tempo e é precioso. Enviaremos o link da nossa sala via WhatsApp, quinze minutos antes do horário de início de cada sessão diária. Verifique antecipadamente a sua conexão de internet wifi e/ou 4G, e a bateria do seu dispositivo. Mantenha seu carregador próximo a você.

Enigma 01 - A casa, ou, feliz dia das mães

(Foto de mulher sentada no que restou de sua casa, após despejo e demolição de uma das ocupações no Distrito Federal a mando do Governador Ibanes Rocha (MDB). Veiculada mídia em abril de 2021.)

Enigma 02 - Os sonhos

A partir de hoje, todos os dias antes de ir dormir, levar para o quarto o celular, 
um caderno e um lápis. A cada manhã, assim que acordar:

20

- Pegar o celular, o caderno e o lápis;

- Ajustar o timer do celular para 03 minutos;

- Iniciar o cronômetro;

- Escrever em fluxo até o timer disparar;

- Repetir esse procedimento até o último dia da Oficina

Enigma 03 - As Imagens

Antes de ler a lista* abaixo, escolha um número de 01 a 10. Seja honesto com você mesmo e seu trabalho.

1. Fotografia é adivinhação

2. A fotografia nasce da espera

3. Toda fotografia é uma sobrevivente

4. Fotografia é assombração

5. Há sempre uma fotografia que nos está destinada

6. Toda fotografia é o tempo que nos resta

7. Fotografar é criar reservas de futuro

8. Toda fotografia está grávida de sonhos

9. Toda fotografia está viva

10. O futuro da fotografia somos nós

Guarde e traga com você a frase correspondente ao número que você escolheu. Banhe-se, nutra-se e respire com ela quando for urgente.

(*Lista com 10 proposições acerca do futuro da fotografia e dos fotógrafos do futuro, do artista Maurício Lissovsky)

Caso haja alguma dúvida, respire e brinque com ela”.

Como se percebe no e-mail, cada um dos enigmas enviados dispara provocações sobre os três grandes territórios de investigação da oficina "Só os sonhos não temem o contágio":

1 - A casa: posta também como mapa das condições sociopolíticas de um país em ruínas;

2 - Os sonhos: enquanto possível caminho de autoconhecimento através do 
acesso às forças do inconsciente;

3 - A imagem: na relação pessoal com os processos de criação dos participantes.

Vale destacar ainda que a decisão de nomear os programas como Enigmas tem o intuito de gerar um deslocamento paradoxal do ponto de vista pedagógico em relação ao próprio entendimento dos programas, vistos usualmente como enunciados claros e objetivos, segundo elaboração de Eleonora Fabião (2008). Elaboração essa já amplamente debatida em nossos artigos anteriores. Essa operação de nomear programas de Enigmas surgiu também a partir da aproximação de conteúdos acerca da sintaxe da imagem fílmica na relação corpo/câmera, assunto também abordado na oficina. "Toda imagem precisa ter um enigma", nos disse o cineasta René Guerra, durante nossos encontros na IV Residência Artística do Projeto cAsa.

Ao longo da oficina, seguimos provocando conteúdos relacionados aos sonhos, em seus múltiplos sentidos pelos mais variados caminhos. Outro exemplo desse processo são os programas de desapresentação ${ }^{12}$ a partir dos sonhos, realizados ao início de cada sessão síncrona. E ainda tivemos o que chamamos de "Efeito Sample sonhos": trechos dos materiais narrados pelos participantes nessas apresentações pessoais e que voltavam ao longo da jornada do dia, recriados em narrativa lançadas pelos integrantes do Fuga!. Optamos, inclusive, por samplear por aqui também alguns dos sonhos narrados coletivamente na realização desses programas, como forma de contornar nossa escrita. Assim, ao longo do texto, traremos o Desapresentar-se 1, 2 e 3 como essa voz que inclui também os sonhos dos participantes da oficina.

Desapresentar-se 1 - Apresentar-se em 01 minuto, a partir de um sonho que você nunca esqueceu:

Nessa praia, todas as crianças se chamavam Antônio, mais de três mil crianças juntas na frente do mar. Os Antonios usavam os sonhos como premonição quando faltava o ar. Uma grande onda os engoliu e levou

\footnotetext{
${ }^{12}$ Ao longo da pesquisa do Projeto cAsa, elaboramos alguns programas de desapresentação utilizados em nossa oficina presencial "Desculpas Cotidianas para dançar". De maneira geral, esse tipo de programa pretende abrir espaços de observação de si e o outro, gerando deslocamentos na forma como escolhemos nos apresentar para um grupo de desconhecidos.
} 
todos os seus sonhos. Ela sonhava que a escola estava vazia. Ela não sonhava muitas vezes, na verdade ela cresceu e percebeu por um momento que ela não gostava tanto assim de sonhar. Mas o que será que tinha nesses sonhos? Ela chora acordada, sonhando pra encher rios, pra encher mares. Eu sonho tanto, tanto, tanto que... O coração quer sair do peito como um passarinho. O sonho tem um tom de pesadelo, mas não é um pesadelo. Sentada em saturno, ela sonha e observa. Ela chora acordada, sonhando arrancar todos os pintos dos homens machistas do mundo. Ela não se lembra dos sonhos. Ele está sonhando dentro de seus sonhos. Ela sonha que voa por cima do seu corpo.

02 - Grupo do WhatsApp, casa temporária

O aplicativo de WhatsApp se apresenta como um dos territórios estruturantes da nossa oficina tanto como campo dramatúrgico quanto como lugar de encontro para o jogo. Assume-se aqui o tempo do acontecimento no cotidiano de cada participante numa dinâmica assíncrona. Horários são préestabelecidos ao longo do dia para abertura e fechamento dos comentários no grupo, bem como para que os enigmas sejam enviados e respondidos até o momento de irem dormir. Abaixo, trecho de uma das instruções de produção para abertura do grupo no aplicativo:

DIA 07/04/2021 - Quarta

o8h - Abrir o grupo pela manhã, enviar primeira mensagem com instruções de uso do zoom + ter sempre caderno e caneta:

"Olá, bom dia! Como vão vocês hoje?

Sejam bem vindes ao nosso grupo Só os sonhos não temem o Contágio! >> Alguns lembretes importantes:

1. Mensagens pontuais chegarão no início da manhã (entre 08h-11h) e do fim de tarde (entre 16h-19h) para o envio tanto de Enigmas quanto o compartilhamento de seus respectivos acionamentos;

2. O funcionamento dos comentários aqui será desativado fora dos horários predeterminados;

3. Tenha sempre caderno e caneta junto a você durante os dias da nossa oficina;

4. Quanto ao Zoom:

Nossa oficina acontecerá na plataforma Zoom Meeting em transmissão ao vivo;

Nossas sessões de trabalhos serão gravadas e necessitarão que as nossas câmeras e microfones estejam abertos e em pleno funcionamento, afinal esse é um dos assuntos da nossa oficina;

Por favor, confira antecipadamente estas funções em seus dispositivos (celular elou computador);

O link de transmissão será disponibilizado aqui na sexta feira pela manhã. 
A cada dia, a conversa é estabelecida e encadeada por uma sequência de ações programadas que se intensificam e se retroalimentam na medida em que os participantes se envolvem e se posicionam com elas, mesmo que isso implique numa ausência de resposta. Cria-se assim uma comunidade temporária, um micromundo de abordagem numa temporalidade expandida até o dia do encontro síncrono entre todas/es/os.

Esta fase da oficina é um primeiro momento de aproximação e encontro entre os participantes. Os movimentos aqui produzidos propagam-se ainda em camadas mais sutis e individuadas, e gradativamente vão ocupando um âmbito mais coletivo, na medida em que o contágio das ações de cada participante infecta o olhar, o movimentar e o fazer das/es/os outras/es/os. A não obrigação do compartilhamento do que é produzido/acionado pelo enigma, independente que seja nomeado como processo ou resultado, é propositalmente comunicada, entendendo-se que a autonomia do participante e a implicação com a proposta é uma escolha pedagógica.

03 - Zoom Meeting, casa sonho ou suando juntos imagem e movimento

Na relação tempo-espacial entre os territórios corpo, casa, câmera e aplicativo Zoom Meeting, descobertas de percursos e corporalidades são acionadas em cada encontro, disparadas pelos programas performativos em combinação com a condução de propostas da Técnica Klauss Vianna13.

Como vai você hoje? Onde está a sua respiração agora? Quais áreas de expansão ou recolhimento se manifestam no seu corpo? E a casa, como ela se movimenta neste momento? Cheia ou vazia? Fria ou quente? O que se revela neste enquadramento da tela? O que reverbera no extraquadro? O que permanece?

Cartográfica e pedagogicamente, vamos averiguando possibilidades de ângulo 
e enquadramento de câmera, bem como da listagem e investigação dos recursos que o próprio aplicativo oferece para que se possa, a partir deles, criar desdobramentos e expandir camadas dramatúrgicas e de ação. Por exemplo, seja na ausência ou na troca dos nomes dos participantes, o simples ato de renomear as janelas na tela do computador e/ ou do celular no início da sessão, já parece produzir e catalisar outros significados que potencializam a narrativa ali construída e compartilhada com todas as pessoas.

Outro exemplo, acontece no dia no acionamento do programa performativo "Entre clichês e máscaras para estar nu". O tabuleiro de jogo estabelecido é a tela da plataforma online. A câmera é o dispositivo de entrada e saída, ligá-la e desligála é a possibilidade de se construir rastros de presença em permanência e/ou ausências, um frame entre nascer e morrer. Em jogos de composição em dupla ou em trio: identificar, reconhecer e transformar criativamente os recursos da plataforma em elos sutis que amplificam sentidos e retorcem códigos cotidianos em matéria de expressão no campo das Artes.

\section{Entre distâncias e bytes, câmeras e telas, como se sonha acordada/e/o?}

O pensamento e o impulso que movem a realização desta oficina são forjados na própria natureza de trabalho que o grupo vem construindo ao abrir constantemente espaços permeáveis aos desejos, dúvidas, anseios, propostas, rastros e outras manifestações do agora que, disparados pelas singularidades presentes, tomam dimensões coletivas no fazer. As ações de trabalho, nesta lógica, acabam por produzir uma rede que envolve reflexões, experimentações, sistematizações, testagens, recriações, e assim a noção que pesquisa e criação engendram um pensamento pedagógico, o qual acionamos em nossas oficinas. Tecer estratégias durante o caminhar, ou no manuseio de nossas questões ver procedimentos tomando forma, nos impele a acionar esse ciclo adiante como maneira de lançar perguntas ao processo enquanto movemos. Dividir questões, coletivizar a experiência para nos manter em movimento.

Assim, pesquisa, criação e compartilhamento de saberes trazem também 
aqui a escrita enquanto prática que atravessa esses territórios anunciando mais perguntas. De forma cartográfica - assumindo a processualidade de cada momento -, palavras, relatos, observações, rascunhos pessoais e coletivos produzem novos mapeamentos abarcando a premissa de que "a política da escrita deve incluir as contradições, os conflitos, os enigmas e os problemas que restam em aberto" (Barros e Kastrup, 2009, p.72). Alcançamos nestas linhas certas esferas que envolvem, em nossa prática de grupo e nos movimentos pedagógicos que nos desafiamos, pensar como a possibilidade de criar uma experiência para si vem organizando um caminho para criar uma experiência para outras/es/os.

Desejamos gerar territórios de escutas e aberturas no plural, buscando arranjos, encontros, investigações e ajustes constantes para o que se anuncia enquanto campo de experimentação em nosso fazer. Partimos de práticas cartográficas enquanto base metodológica e criativa por meio da realização de Programas Performativos que, articulados a premissas da Técnica Klauss Vianna de dança e educação somática, agem como disparadores para a relação entre corpo e ação cênica, e seus desdobramentos pedagógicos.

Tais práticas cartográficas enquanto base metodológica, pedagógica e criativa demandam, contudo, uma série de mudanças de atitude. Essas mudanças são de ordem ética e pragmática, pois o que se desloca antes de tudo são as expectativas em relação ao que uma metodologia pode oferecer e mesmo o que é um processo de pesquisa e criação, e ainda, como eles se desenvolvem.

Nesse sentido, como estamos contornando aqui no texto, o máximo que a cartografia pode nos oferecer é uma rede formada por pistas e dúvidas. Rede essa que não existe a priori, tecendo-se apenas a cada passo com o processo da pesquisa e/ou criação. Ou seja, trata-se de uma rede processual e imanente, estabelecida numa ética dos encontros e das coletividades.

Então, o/a/e artista pesquisador/a/e que se aproxima da cartografia, deve se preparar para primeiramente deslocar sua expectativa de controle sobre a pesquisa e ou criação, assumindo uma postura menos hierárquica, na qual ele é apenas - e isso já é o bastante - mais um agente provocador e acompanhador dos dispositivos em ação. Inclusive, recebendo em si também a força que os 
dispositivos geram, fazendo parte do circuito que faz a pesquisa caminhar.

Dizendo de outra maneira, a/e/o artista pesquisador/a/e cartógrafa/e/o não deve temer a sensação muito comum de estar perdido e sem rumo, nem as dúvidas que surgirão ao longo do caminho. Deve, ao contrário, aproveitar esses momentos para testar a sutileza de sua sensibilidade em perceber o entorno e, no meio do caos aparente, rastrear as vibrações das forças em ação e seus deslocamentos. E, assim, encarando esse estado de perdição como condição, encontrar suas estratégias pessoais de expressão.

Pensemos na imagem de um barco em alto mar à deriva. O senso comum nos diz que este barco está sem rumo, pois não se vê nele um comando que tome as decisões para levá-lo onde deveria ir. A/o/e artista pesquisador/a/e cartógrafa/e/o, contudo, poderá olhar para essa situação percebendo que há sim um certo comando ali, exercido, porém, não apenas por um comandante, por uma força central, mas por um conjunto de forças. Um comando a-centrado, coletivo e processual que se expressa pela conjunção precária e imprevisível das pequenas e constantes forças dos ventos e das marés movidos pelos acasos. Assim, o barco segue movido pelo jogo que se estabelece no campo de forças em agenciamento e sua rota vai se definindo a cada momento. O que deixa de existir, então, é somente o trajeto enquanto rota pré-determinada.

Assim, age-se em busca de uma atenção sutil qualificada para perceber a rede de relações entre as forças que dão rumo ao seu processo. Ao mesmo tempo em que cria as condições para tais forças se expressarem, observa seus desempenhos e, ainda, os efeitos destes desempenhos sobre o campo e sobre ela/e mesma/e/o. Ou seja, há um trabalho em múltiplas camadas simultâneas que precisa ser executado.

Há que se ser errante, disposto a enfrentar marés de dúvidas constantes e a responder criativamente a cada onda que se apresenta. Vale destacar e reforçar ainda que enquanto imagem conceito, precisamos entender que tanto o barco à deriva, quantos os ventos e ondas que impulsionam sua trajetória são dispositivos criados pela/e/o própria/e/o artista. Cabe detectar e escolher seus dispositivos "ventos", "ondas" e "barco"; colocá-los em ação e acompanhar as relações que 
surgem e como elas se transformam.

Ou seja, nas práticas cartográficas desloca-se o próprio jeito de olhar e manejar o método e seus procedimentos; desloca-se a forma de abordagem em relação ao método e deste, por consequência, em relação ao campo pesquisado e ao artista pesquisador. Pois, não há um método cartográfico pronto para ser aplicado. Por ser um saber-fazer e ter seus princípios ancorados na experiência prática, a cartografia se recria a cada vez que é revisitada. Cada qual será forçado a expressar o seu modo específico de articulação, gerado a partir das suas especificidades inerentes.

Então, o que nossa prática vem nos mostrando é que a cartografia não é uma metodologia aplicada e sim um campo metodológico que assume a diferença enquanto ética e privilegia a capacidade de invenção, o aspecto criativo intrínseco a cada pesquisa e criação.

O que tais práticas possibilitam com isso é uma abertura de pensamento e abordagem, convidando-nos a encontrar nossos próprios meios de expressão. É necessário inventar com ela e com o campo pesquisado as características e estratégias de sua composição.

Nesse sentido, prima-se tanto pela capacidade de escuta e de observação com um certo estado de passividade contemplativa que rastreia o entorno quanto pela capacidade de ação criativa e inventividade - como resposta aos acasos que o caminho da pesquisa vai oferecendo. Tal operação duplicada convoca a um comprometimento radical entre os elementos do campo de força criado, despertando os aspectos performativos, convocando-nos a estabelecer um conjunto de práticas que seja capaz de dar conta dos deslocamentos gerados. Assim,

A cartografia surge como um princípio do rizoma que atesta, no pensamento, sua força performática, sua pragmática: princípio 'inteiramente voltado para uma experimentação ancorada no real' (Deleuze e Guattari, 1995, p. 21) [...]. A precisão não é tomada como exatidão, mas como compromisso e interesse, como implicação na realidade, como intervenção (Passos, Kastrup e Escóssia, 2010, p. 11).

Pensar e agir a precisão não enquanto exatidão, mas enquanto compromisso 
e interesse, que vai construindo ao longo do processo afetos de vínculo entre as partes envolvidas. Tal condição de vínculo, baseada sobretudo na confiança mútua que se estabelece, é o que torna um pouco menos instável o descontrole gerado pelas práticas cartográficas. O que se forma é um circuito de forças em afetação constante, no qual os níveis de descontrole e de qualidade de vínculo se retroalimentam e se influenciam. O que nosso processo vem nos fazendo refletir, inclusive, é que quanto mais fortes os vínculos criados, mais a sensação de descontrole torna-se menos desagradável de ser enfrentada.

Todo nosso desafio e esforço durante a oficina é justamente criar a circulação dessa sensação de vínculo pelo trabalho. A cada novo encontro esse desafio se refaz como possibilidade a ser conquistada. Ou ainda, como afirma Suely Rolnik (2011, p.23):

A cartografia, nesse caso, acompanha e se faz ao mesmo tempo que o desmanche de certos mundos - sua perda de sentido - e a formação de outros: mundos que se criam para expressar afetos contemporâneos, em relação aos quais os universos vigentes tornam-se obsoletos [...]. Sendo tarefa do cartógrafo dar língua para afetos que pedem passagem.

Afetos esses que se organizam e desorganizam nos atravessamentos entreintra corpos, em seus estados e potencialidades expressivas.

\section{Entre escutas e ruídos, distâncias e intimidades: a Técnica Klauss Vianna como respiro somático performativo}

O trabalho com a Técnica Klauss Vianna, ao construir territórios entre o somático e o performativo, tensiona certas camadas conceituais e práticas que envolvem a construção do corpo presente e relacional. Nas oficinas ${ }^{14}$ do grupo e nos processos de criação, a Técnica Klauss Vianna vem ancorando modos de investigar construídos a partir da percepção de si, da/e/o outra/e/o, do entorno e de seus acontecimentos, assumindo a rede dinâmica de acordos, ajustes e reinvenções nesse fazer. Pautada na escuta sensível acionada por alguns

${ }^{14}$ As oficinas do grupo, em suas diferentes versões, se orientam a partir de alguns princípios e referenciais comuns para a construção de suas propostas. Tais pressupostos podem ser também encontrados no artigo que discute a oficina intitulada "Desculpas cotidianas para dançar": Rabelo et. al., Desculpas Cotidianas Para Dançar: cartografias de uma prática artística e pedagógica. In: Teatro: criação e construção de conhecimento [online]. Palmas, v.3, n.2, jul.-dez, 2016. p.71-83. 
pressupostos da Técnica ${ }^{15}$, nas práticas o corpo é levado a caminhos de auto observação e provocação de seus estados no agir, no perceber e no sentir. Este movimento vem assim desenhando percursos que atravessam um fazer performativo e somático, interseccionando princípios destas esferas que passam a atuar de forma co-dependente, e que se atualizam na pesquisa de cada participante que os maneja a partir de seus campos autorais.

Como estrutura para a oficina, nos propomos a pensar a construção da escuta do corpo, a partir do proposto por Miller e Laszlo (2016), que os organiza em 4 possíveis estados de atenção para o estudo e manutenção da presença, que envolvem abrir à percepção: 1- ao corpo e seus processos em atualizações com o momento presente; 2- ao espaço e suas modulações; 3- à relação com as/es/os demais participantes presentes no trabalho; 4- à cena, observando e reconhecendo suas transformações ao estar nela. Para cada um dos dias da oficina, foi proposto o enfoque em um estado de atenção específico, mas sempre entendendo a intrínseca relação entre eles e a consciência de que, na construção e manutenção da presença, há um jogo dinâmico entre essas esferas. O perceber negocia o vetor dinâmico da escuta, que pousa ora em um e ora em outro campo e que, nesse movimento, acaba por ser responsável por nos engajar, em nossa completude, na ação do corpo, do espaço, da/e/o outra/e/o e da cena e suas variações. Assim, os 4 estados de atenção são acionados a todo tempo no trabalho na Técnica Klauss Vianna para a construção da presença, mas aqui, durante as práticas, escolhemos trazê-los com ênfases diferentes a cada dia.

Assim, para o primeiro dia de oficina, no conjunto de nossos acionamentos, escolhemos dar destaque à atenção ao próprio corpo e seus estados. Propomos despertar as sutilezas do sentir, do ato de se tocar, de se perceber tocando e também sendo tocado pelas diferentes temperaturas, sons, texturas, pensamentos e sensações vindas de si e do entorno. Escutar-se até o reconhecimento da respiração, dos ritmos internos na exploração da mobilidade articular, tendo como premissa assistir-se, assistir ao próprio movimento

15 Nos baseamos nos princípios sistematizados da Técnica Klauss Vianna, a partir do estudo de Jussara Miller (2007), que se estruturam em três estágios: processo lúdico, processo dos vetores e processo criativo. Para este trabalho, acessamos os tópicos corporais trazidos no processo lúdico (presença, articulações, peso, apoios, resistência, oposições e eixo global), em uma dinâmica de pesquisa que constantemente os intersecciona. 
enquanto ele se realiza dando formas e ajustes temporários ao corpo. Por onde você escolhe se assistir? O que você assiste em si mesma/e/o? Nesta provocação cinestésica, as percepções do espaço interno e externo operam em deslizamento e transformam esse duplo reconhecimento num deslocar, que transborda o quadro delimitado pela tela. Os programas disparados após esse momento, somados às provocações dos programas de abertura, vão construindo formas de cada um/a/e se integrar ao espaço íntimo da casa e disparar escolhas quanto ao que se revela no quadro e ao que fica fora dele; ao que se deseja ser, narrar, não ser, ou mesmo sonhar dentro dele, e ao que se decide ser construído num extraquadro.

O segundo dia de oficina é movido pela proposta de se intensificar a relação com o espaço e a escuta de suas ambiências. A premissa de recolher e expandir o corpo e seu entorno, desde uma pulsação interna até uma intenção compositiva com o ambiente, se estrutura a partir da noção do apoio ativo e da resistência nas expansões e alcances, assim como no ceder e recolher, sempre em sustentação. o que expande dentro e o que recolhe fora a partir do que eu movo? o espaço move? Que encaixes e desajustes ele traz? O que ele compõe? O espaço pode ser uma camuflagem? Observando a casa e a ação de se misturar a ela, e assim contaminar o movimento pelo o que se observa, trazemos a atenção para os detalhes da casa: fissuras, ranhuras, marcas, degradações, infiltrações. Como o corpo também se infiltra nesse espaço? Como o corpo responde a essas imagens? Que composições são criadas? Como o corpo enquadra, se opõe, sublinha, esconde, revela esses detalhes? Como eu os encontro, os escolho, os abandono e também me transformo em parte dessa composição? Como me torno ruína desse espaço? Os programas seguintes vão procurando dar contornos a esses acionamentos e estruturar ações compositivas, entrecortadas por narrativas coletivas.

O trabalho com enfoque nos estados de atenção a si e ao meio, como proposto nos dois primeiros dias de oficina, vem a desafiar as possíveis relações com a/e/o outra/e/o, aqui mediadas pela tela, como direcionamento para o terceiro e último dia de trabalho. É importante ressaltar que estado de atenção 4, em relação à cena e suas transformações ao estar em cena, foi sendo convocado 
dia a dia em propostas nas quais o pensamento compositivo se estruturava como pesquisa de movimento, provocados pela Técnica Klauss Vianna, e também como ação, quando disparados pelos programas.

Para o terceiro dia, deixando ainda ecoar o programa de abertura, nos propusemos conduzir coletivamente toda a chegada no corpo, nos escutando, nos lendo enquanto presenças virtuais na tela. A condução buscou ser feita na escuta de todas/es/os, no tempo que todas/es/os sustentariam juntas/es/os. Nesta trajetória de aquecimento e chegada, deveríamos escolher por onde cada corpo queria ser visto, por onde ele aqueceria sua imagem na tela, manuseando assim o dispositivo câmera em função dessas escolhas. Escutando a necessidade do momento, nos propusemos nos autoconduzir ativando duas camadas - as premissas de movimento que experimentamos nos dois dias anteriores e uma observação e provocação no/do corpo da/e/o outra/e/o. Observar a/e/o outra/e/o, se contaminar com o movimento da/e/o outro, roubar detalhes, pegar pra si o que viu em um frame, em um relance que fosse. O que você vê do quadro do outro, que vaza do quadro do outro, do extra quadro do outro? Como percebo o outro, o meu espaço e a mim mesma/elo? Como você pode trazer a/e/o outra/elo para sua dança? Ou como você pode imaginar esse aquecer com ela/e ou com elas/es? É possivel sonhar uma dança coletiva? Que encontros você sonha nessa dança, neste aquecer?

Levamos esta proposta envolvendo encaixes com pausas/suspensões/respiros, explorando os apoios, sustentações, alcances e recolhimentos, preenchendo o espaço, detalhando o entorno e o interno. Então, nos propusemos explorar a casa buscando lugares de risco, situações de vulnerabilidade e acolhimento, e a partir disso deixar os estados reverberarem como composições, levando a câmera para dar contornos a sua exploração.

A prática somática, neste movimento tensivo, se revela como campo epistemológico contemporâneo associada à pesquisa na criação artística, conforme trazido por Ciane Fernandes (2015), escapando assim de delimitações mais comuns que poderiam restringi-la a certos contextos e demonstrando sua capacidade de articular diferentes formas do saber. Afirma que, todos os somas propõem movimentos paradoxais entre equilíbrio e mudança, padrões cíclicos 
alternantes, tendem à autonomia e independência de seu meio enquanto tendem a desejar e depender dele, adaptando-se, em direção à diferenciação e integração. Resistência e aderência, conforme Fabião (2008), aderir para pertencer e criar modos de resistir e haver relação, diálogo. A perspectiva somática organiza uma noção de corpo que resiste e adere, se alimenta nos paradoxos e por isso produz vida.

De fato, a somática desestabiliza inclusive a ênfase contemporânea no corpo, trazendo algo tão aparentemente simples como a pulsão de vida no continuum espaço-tempo como fundamento constituinte e, por isso mesmo, revolucionário e de aplicação irrestrita: "Organismos vivos desafiam ser descritos como 'corpos'. Eles têm uma ordem movente e uma legalidade em si mesmos que viola o conceito estável de 'corpo'. Organismos vivos são soma...” (Hanna, 1976, p. 31). Nesse sentido, soma é uma interação que dilui a objetificação do corpo em prol da autonomia do ser vivo integrado em todas as suas instâncias, multiplicidades e idiossincrasias, inclusive constituído como paradoxal e metafísico, autocoordenando-se holisticamente rumo ao próprio crescimento com o/no meio (Fernandes, 2015, p.13).

Os paradoxos se instauram como movimentos de encontro simbiótico com o fazer performativo, em um duplo que envolve pergunta e escuta ao corpo, aos acontecimentos, aos impulsos, ao que se pauta como possível ação, e ao que se imagina realizar. A simultaneidade do agir e perceber, colocada como desafio e necessidade no trabalho, busca um corpo em relação a partir de suas instâncias físicas, cognitivas, imagéticas, sensoriais, em atenção e negociação constantes com seu meio, gerando espaços de aprendizado e troca.

A Técnica Klauss Vianna, enquanto acesso ao soma, é proposta na oficina como território de entrada e abertura à percepção das dramaturgias que rodam os programas disparados, ou aqueles ainda a serem construídos, convidando inclusive possíveis conexões não previstas para o compor das ações. Espaços sempre relacionais de experiências coletivas, aprendizados coletivos e por isso arranjos coletivos no constante dentro e fora dos integrantes do grupo e das/es/os participantes. A imprevisibilidade do sensorial acaba por reorganizar rumos traçados e nos fazer assumir mudanças. Ao assumi-las, jogamos com ajustes constantes e somos convocados a tomar decisões sempre temporárias.

Assim, no campo de trabalho com perguntas e enigmas, deve-se assumir que 
o oculto é um território possível, de emergências, abandonos e encontros. Envolve tanto aquilo que se pressiona a ser dito, quanto ideias, procedimentos e escolhas que pedem por ser esquecidos para que outra coisa venha. Enquanto propositoras/es, passamos a nos perguntar o que estaria oculto para nós em cada trabalho, em cada programa, o que esse movimento de dar contorno às ações nos aciona. Que perguntas estamos nos fazendo quando entramos em uma oficina? As/es/os participantes seriam aquelas/es responsáveis por reanimar os enigmas? Adaptabilidade e pulsão, as dimensões somáticas do trabalho, concebendo a processualidade do nosso fazer como estratégia de sobrevivência.

Associado à somática, o performativo não é primeiramente associado a "[...] como fazer coisas com palavras" (Austin, 1962), mas sim como mover e ser movido pelo ambiente pulsante, que inclui coisas, palavras, textos, células, líquidos intra-, inter- e transcorporais, objetos, paisagens, planetas etc. Nesse espaço transcelular conectivo, experienciamos como a pesquisa se move e se organiza e como ela nos move a escrever com ela, ao invés de a respeito dela (Lepecki apud Fernandes, 2015, p.27-28).

O performativo e o somático nesta oficina vem delineando, enquanto estamos mediados pela tela, espaços de escuta e ruídos, conexões e ausência, pausa e agitação, de distância e intimidade por meio de estratégias de contágio. Contágio com ideias, possíveis, contágio com o mundo.

Desapresentar-se 2: Apresentar-se em 01 minuto a partir de seu último sonho.

Ele se acha fraco diante do pai enquanto troca a sunga. O chão era muito delicado ele quebrava toda vez que ela tinha que falar com a família dela, ela tinha que pisar bem devagar. A textura das costas dela era como um morango. Ele não lembra do sonho de hoje, ele carrega o sonho de hoje no corpo, mas lembra do sonho de ontem e de anteontem. Ele tem a sensação de mar no corpo. Ela sonha que está viajando e levando a casa com ela. Ela vai casando com os lugares por onde passa... ela fez todo esse percurso para casar com ela mesma. Ela tinha achado em si mesma a própria casa, ela era o mar. Ela sonhava com as frutas dos pés da casa da Infância. Ele não sonha, ele está acordado no meio de uma casa antiga, longe do mar. A sensação é de que sempre falta alguma coisa pra terminar, como se ele acordasse com a sensação de que o sonho ainda ficou reverberante, como se ele ainda precisasse resolver alguma coisa. Ela foi pro mar e o biquíni dela saiu e além dela mesmo não restava mais nada... nas águas, ela encontrava força e quando ela saía das águas ela não se importava mais, ela era o mar. E também tinha uma sensação de 
futuro. Ela não sonha, ela está acordada. Ela não sonha, mas acordou com uma música.

\section{Movimentos entre aberturas e germinações de futuros}

Os trajetos esboçados até aqui, abordam a experiência de uma oficina convocada em tempos de escassez, pautada em uma pedagogia processual, paradoxal, coletiva, que em meio ao sufoco e o escancaramento de violências, misérias e políticas de morte, pode ser lida como proposta/dispositivo de mobilização de materialidades visíveis e invisíveis. Numa tentativa de abertura de espaços de troca que amplifiquem as possibilidades de decodificar das urgências do agora. Urgências essas fundadas tanto nas falências das formas do presente, que nos tornam inférteis por estarem desgastadas em suas forças vitais, quanto na necessidade de fecundar-se de outros imaginários e mundos, possíveis e impossíveis.

Transitando pelos meios de aproximação que nos restam em tempos de restrições entre corpos e afetos presenciais, buscamos a escuta do corpo em algumas de suas manifestações conscientes e inconscientes, esboçadas no interno e no entorno, como possibilidade de vislumbrar muitas versões de nós mesmas/os/es, nas vastidões abrigadas em cada um/a/e.

Um convite ao sonhar junto a partir da micropolítica ativa, como aponta Suely Rolnik (2018), que neste caso atravessa todas as instâncias do trabalho, do e-mail de abertura, passando pelas práticas corporais, ao modo como este artigo é redigido, criando condições para espreitar alguns germes de mundo que nos habitam em estados ainda larvais, posto que, conforme esta autora:

O que move os agentes da insurreição micropolítica é a vontade de perseveração da vida, que nos humanos se manifesta como impulso de "anunciar" mundos por vir, num processo de criação e experimentação que busca expressá-los. Performativizado em palavras e ações concretas portadoras da pulsação desses gérmens de futuro, tal anúncio tende a "mobilizar outros inconscientes" por meio de "ressonâncias", agregando novos aliados às insubordinações nessa esfera. Os novos aliados, por sua vez, tenderão a lançar-se em outros processos de experimentação, nos quais se performatizarão outros devires do mundo, imprevisíveis e distintos dos que os mobilizam (Rolnik, 2018, p.131). 
Trata-se então de uma tentativa de reconexão com saberes do corpo que permitem ouvir aquilo que quer perseverar a vida como potência de transfiguração, dando passagens aos impulsos do desejo como força que nos move à produção de realidades outras, em modos diversos de ver, sentir e agir. Desejo este orientado pelo sentido de responder às inquietações colocadas pelas rupturas com os modos habituais de fazer e pensar a arte, a dança, a performance, as relações, as percepções, as respostas cotidianas e a própria ideia de criação, que busca em suas ações conectar-se a parâmetros inabituais inesperados, irrisórios e novos, no intuito de abrir "vias de passagem para a germinação e o nascimento do referido embrião de mundo que habita silenciosamente o corpo" (Rolnik, 2018, p.60).

Na experiência desta oficina, na qual as alianças se afirmam pelo contágio configurado por forças nem sempre dizíveis, por se traduzirem em idiomas ainda desconhecidos, tentamos, através das atmosferas transgressoras dos sonhos, impulsionadas pelas estratégias performativas propostas, transitar por outras sensibilidades, outras dobras, outras palavras, outros movimentos, outras imagens, outras memórias, que possam acolher os impensáveis como gestos possíveis, produtores de realidades co-criadas, portadoras de inúmeras camadas de real.

Neste sentido, os encontros com as outridades vislumbradas em cada vivente, aqui conectados pelos dispositivos tela, computadores, celulares, programas performativos, danças, enigmas, imagens, sonhos e outras reverberações, torna o encontro virtual uma comunidade provisória, ancorada na vontade de decifração e expressão. Um modo irrisório de sustentar-se juntas/os/es na deriva, como possibilidade de "suspender o céu", como nos dirá Ailton Krenak (2019, p. 32), ampliando horizontes existenciais e artísticos. Fertilizando nossas subjetividades com matéria viva e não com o caldo mortificante que quer se impor pelas lógicas colonizadoras do corpo e do inconsciente, tão conhecidas em suas diversas modalidades de expropriação da vida em todos os seus sentidos, e que por vezes parecem nos engolir em uma terceira onda de inseguranças devastadoras, seja pelo saldo de mais de 491.164 corpos desaparecidos, seja pela precarização que atinge as formas de vida atuais.

Deste modo, sonhar passa a compor mais uma esfera das realidades vividas, das memórias recriadas e dos futuros gestados aqui e agora, dos atos de criação 
que são indícios de um porvir implicado a outras dimensões da vida, para além das produtividades impostas e das objetividades massificantes e homogêneas, como nos afirma Krenak (2019, p.65-66):

De que lugar se projetam os paraquedas? Do lugar onde são possíveis as visões e o sonho. Um outro lugar que a gente pode habitar além dessa terra dura: o lugar do sonho. Não o sonho comumente referenciado de quando se está cochilando ou que a gente banaliza "estou sonhando com meu próximo emprego, com o próximo carro", mas que é uma experiência transcendente na qual o casulo humano implode, se abrindo para outras visões da vida não limitada. Talvez seja outra palavra para o que costumamos chamar de natureza. Não é nomeada porque só conseguimos nomear o que experimentamos.

Assim, "Só os sonhos não temem o contágio" surge como tensionamento para provocar a relação entre arte, inconsciente e resistência, no sentido de nos lembrar que as crises aportam revoluções em potencial e que os modos como endereçamos nossas necessidades de transmutação são práticas éticas, políticas e estéticas, nas quais decidimos, por ajustes temporários e apostas provisórias, proliferar sementes de vida ainda sem nome, que desvelam estados de criação singulares e coletivos ${ }^{16}$.

Em um momento em que abraços, suores e afagos são distantes, em que dores e fraturas aparecem tão expostas, em que o medo é presente em quase todas as células do corpo e do social, reiteramos a importância dos levantes norteados pelo princípio do comum que se estabelece no entre, no fazer junto. Comum este que, como nos dirão Marina Guzzo, Conrado Federici e Flávia Liberman (2019, p.112), se dá como experiência de abertura ao que "aparece justamente nas frestas, nas fendas, nas fraturas, no que se estabelece de novo, a partir de uma proposta aparentemente "incabível" ou "difícil" ou “impensada”(Guzzo; Federici; Liberman, 2019, p.112), ou ainda, naquilo que gera pertencimento a partir da diferença, do estranhamento, da alteridade, das comunidades temporárias, em que nos despimos de certezas para sondar

${ }^{16}$ Enigma horizonte: - Respirar, espreitar e olhar em volta, dentro e fora; - Encontrar um horizonte possível na ruína; - Realizar um registro de vídeo com duração de 15 segundos; - Enviar o vídeo no grupo do WhatsApp às 11h35. Para assistir ao vídeo colagem com os Horizontes enviados pelos participantes: https://youtu.be/nZkYcowbBql 
reconfigurações, deslocamentos e outros registros sensíveis ${ }^{17}$.

Desapresentar-se 03: Apresentar-se em 01 minuto a partir de um sonho de futuro:

Ele sonha carnavais com multidões aglomeradas, suor e glitter. Multidões de todos os tipos, cardumes e pássaros voando, sonha que ela vai chegar em todos os lugares que ela quiser. Sonha com crianças correndo, que vai ouvir as histórias da avó para encontrar ela mesma, que não vai ter tanto medo. Sonha sorrisos e movimento. Ela sonha com cuidado, sonha um outro tempo. Sonha não ter desesperança, ter outros sonhos junto com muitas pessoas. Ela sonha vacinas, sonha mais horizontes e conversas ao pé do ouvido. Nunca mais voltar para onde estamos. Ela sonha com uma sala com gente suada sonhando. Ela sonha em andar por aí sem planejar, abraçar estranhos, beijar estranhos, ser ela e ser outres. Eu sonho... não, ela sonha. Ela sonha que ela possa ser um pouco mais ela, eu sonho que... não, ela sonha que ela pode ser professora. Eu sonho que eu quero ser... não, ela sonha que ela pode ser livre, ela pode ajudar outras pessoas. Eu sonho que lá na frente a gente possa se encontrar... não, ela sonha que ela vai estar muito bem numa estrada de chão com um monte de gente aglomerada, com o cu pra cima, junto com as irmãs dela e ninguém passando fome, todo mundo sendo amada e amade. Eu sonho que isso pode acontecer em breve e que a gente possa voltar a sonhar porque eu acho que... não, ela acha que sonhar já não era mais uma possibilidade... eu sonho que... não, eu não consigo sonhar... ela sonha que ela sonhasse mais, que pudesse ser um sonho mesmo. Ela sonha que a presidenta do Brasil é uma travesti preta. Sonha reencontros. Sonha um tempo para que as coisas tenham um tempo para pensar o tempo com um novo cuidado. Ela sonha com o filho que ela pode gerar.

\section{Referências}

BARROS, Laura Pozzana de; KASTRUP, Virgínia. Cartografar é acompanhar processos. In: PASSOS, Eduardo; KASTRUP, Virgínia; ESCÓSSIA, Liliana. (Orgs.) Pistas do Método da Cartografia: pesquisa-intervenção e produção de subjetividade. Porto Alegre: Sulina, 2009.

FABIÃO, Eleonora. Programa Performativo: o corpo-em-experiência. Revista /linx,

17 Para assistir vídeo com depoimento do participante Emi Mateus/Afroqueer, durante último encontro síncrono da oficina: https://youtu.be/cfu1sTpRpNE 
Campinas, n. 4, p. 1-11, dez. 2013. Disponível em: <http://www.cocen.rei.unicamp.br/revistadigital/index.php/lume/article/view/276> . Acesso em: 29 out. 2016.

FABIÃO, Eleonora. Performance e teatro: poéticas e políticas da cena contemporânea. Sala Preta, São Paulo, v. 8, p. 235-246, nov. 2008. ISSN 2238-3867. 196 Disponível em: Acesso em: 03 jun. 2021.

FERNANDES, Ciane. Quando o Todo é Mais Que a Soma das Partes: somática como campo epistemológico contemporâneo. Revista Brasileira de Estudos da Presença, Porto Alegre, v.5, n.1, p.9-38, jan./abr. 2015.

GUZZO, Marina; FEDERICl, Conrado; LIBERMAN, Flávia. Descolonizar a arte: Território, comunidade e esfera pública. Moringa Artes do Espetáculo, João Pessoa, UFPB, v. 10 n. 2, p. 107-124, jun.-dez./2019.

KRENAK, Ailton. Ideias para adiar o fim do mundo. São Paulo: Companhia das Letras, 2019.

MILLER, Jussara Corrêa. A escuta do corpo: sistematização da Técnica Klauss Vianna. São Paulo: Summus, 2007.

MILLER, Jussara; LASZLO, Cora. A sala e a cena: a importância pedagógica de processos criativos em dança e educação somática". Cadernos do Gipe-C/T Ano XX, n.36, Processos Criativos: Educação Somática e Afetos. Salvador, set. 2016.

ROLNIK, Suely. Cartografia Sentimental - transformações contemporâneas do desejo. Porto Alegre: Sulina: Editora da UFRGS, 2011.

ROLNIK, Suely. Esferas da Insurreição - Notas para uma vida não cafetinada. N-1 Edições, São Paulo, 2018.

Recebido em: 15/06/2021

Aprovado em: 29/09/2021 